\title{
Agent-Based Modelling in Population Studies
}

\author{
edited by André Grow and Jan Van Bavel \\ Dordrecht: Springer, 2017 \\ ISBN 978-3-319-32281-0 \\ Hardcover US\$159.99, eBook US\$119, 513 pp.
}

\section{Reviewed by Thomas K. Burch \\ University of Victoria}

This volume is a selection of papers, peer-reviewed and revised, from a 2014 conference on agent-based modeling (ABM) in demography that took place at the University of Leuven in Belgium. It provides an up-to-date and authoritative picture of the state of the art of ABM and related computer modelling techniques as applied to human population dynamics.

Without exception, the authors are at the forefront of the field. The papers are relatively advanced, with technical details that assume readers are skilled in mathematical and computer modelling, mathematical statistics, and/or computer programming, or some combination. This is not an introduction to agent-based modelling.

ABM is inherently complex and difficult-more so, for example, than most traditional demographic techniques, standard multivariate analysis, or some other methods of computer modelling, such as systems dynamics. Prskawetz comments: "Agent-based modelling requires a good knowledge of tools in computer simulations, but also in statistics and probability theory. Developing the formal behavioural rules and interactions of agents also requires some skills in mathematical formalization" (p. 71). Richiardi and Richardson note that "...large-scale simulation projects are generally beyond the reach of a single scientist.... Simulation modelling needs cooperative development" (p. 111). For this reason, it is unlikely that ABM will become part of the everyday toolkit of the average demographer. It will remain the province of a small number of specialists, just as has been the case with mathematical demography or previous demographic microsimulations. But this is not unusual in science; even a small discipline like demography can benefit from a division of labour.

Before reading this book, the ABM novice might explore the technique using simple models on such free websites as Insight Maker or NetLogo. Associated with the latter is an elementary introduction to ABM by Wilensky and Rand (2015). A similar text is available from AnyLogic, along with a free "light" version of their powerful modelling software (which is expensive in the full version).

Most demographers will find that some chapters are more congenial than others. Ch. 13, for example, by Klüsener, Scalone, and Dribe, deals with familiar questions regarding diffusion in fertility transitions, and is firmly anchored in the literature. Similarly, the chapters by Willekens (10), Prskawetz (3), and Wolfson, Gribble, and Beall (17) provide a nice balance between demographic substance and modelling technicalities. 
As might be expected in a relatively new field, there is some lack of standardization regarding definitions and procedures. At times, the distinction between $\mathrm{ABM}$ and classic microsimulation is blurred. In ABM the behaviour of an agent is "rule-based," but the nature of the rules is not always clear (cultural norms, in-group beliefs, laws?). In some cases, behaviour also is based on social pressures deriving from the agent's position in a social network. In many others, behaviour retains some stochastic elements, as in older microsimulations. Willekens, for example, explicitly states that his model (Ch. 10) "...is referred to as a simulation model, not an agent-based model" (p. 258). It is a formalization of a decision process that could later be integrated into a larger ABM.

So, while not a systematic introduction to the field or even an advanced text, this book likely will remain as a landmark on the way to the assimilation of agent-based modelling into demography. In chapter after chapter, one encounters models that provide new insights into familiar demographic dynamics. And the whole enterprise is placed in broad scientific context in the substantial introductory chapters by editors Van Bavel and Grow (Ch. 1), and by Courgeau, Bijak, Franck, and Silverman (Ch. 2).

The last six names are a reminder of the fact that of the twenty-five or so contributors to the volume, only five are from North America. Europe is the clear leader in the adoption of ABM, and perhaps computer modelling generally, which poses an interesting question in the sociology of demography.

Note: The book lacks an index, so the reader interested in tracking down specific topics or authors will be more successful doing computer searches of the e-version.

\section{Reference}

Wilensky, U., and W. Rand. 2015. An Introduction to Agent-Based Modeling: Modeling, Natural, Social and Engineered Complex Systems with NetLogo. Cambridge: MIT Press. 